\title{
Priming with rocuronium accelerates neuromus- cular block in children: a prospective randomized study
}

\author{
[L'amorçage avec le rocuronium accélère le bloc neuromusculaire chez les enfants: \\ une étude prospective randomisée]
}

Matthias Bock MD DEAA, ${ }^{*}$ Lars Haselmann MD, $†$ Bernd W. Böttiger MD PhD, $†$ Johann Motsch MD PhD $†$

Purpose: To determine the effects of a priming technique with respect to onset time and duration of action of rocuronium (I.5 $\left.\times \mathrm{ED}_{95}, 2.0 \times \mathrm{ED}_{95}\right)$ in a pediatric patient population.

Methods: Eighty-four children, age one to seven years undergoing elective pediatric surgery, were studied in a randomized controlled trial. Neuromuscular function was assessed by accelerometry in response to single-twitch stimulation to assess onset of neuromuscular block, followed by train-of-four (TOF) stimulation at the wrist every $15 \mathrm{sec}$. Children were randomly allocated to one of four groups: Groups I and 3 received saline placebo, followed one minute later by a single bolus dose of rocuronium $0.45 \mathrm{mg} \cdot \mathrm{kg}^{-1}$ iv $\left(\mathrm{I} .5 \times \mathrm{ED}_{95}\right)$ and $0.6 \mathrm{mg} \mathrm{kg}^{-1}$ iv $(2.0$ $\left.\times \mathrm{ED}_{95}\right)$, respectively. Patients in Groups 2 and 4 received an initial dose of rocuronium $0.045 \mathrm{mg} \cdot \mathrm{kg}^{-1}$ iv and $0.06 \mathrm{mg} \cdot \mathrm{kg}^{-1} \mathrm{iv}$, respectively, followed one minute later by rocuronium 0.405 $\mathrm{mg} \cdot \mathrm{kg}^{-1}$ and $0.54 \mathrm{mg} \cdot \mathrm{kg}^{-1} \mathrm{iv}$, respectively.

Results: Rocuronium priming significantly accelerated the time to maximum rocuronium-induced neuromuscular block when compared to placebo [median (95\% confidence interval)]: I 22.5 (98-186) vs 92.5 (68-1 I6) sec (I.5 × ED 95 , Group I vs Group 2, $P<0.05)$ and $85(60-142)$ vs $55(48-72) \sec (2.0 \times$ $\mathrm{ED}_{95}$, Group 3 vs Group 4, $\left.P<0.05\right)$, respectively. Spontaneous recovery to a TOF-ratio $\geq 0.9$ was dose-dependent and not influenced by priming.

Conclusion: Priming accelerated the onset of rocuronium in children. A priming interval of one minute and a cumulative dose of rocuronium $1.5 \times \mathrm{ED}_{95}$ resulted in an onset of neuromuscular block comparable to a single dose of rocuronium $\left(2.0 \times \mathrm{ED}_{95}\right)$.
Objectif : Déterminer les effets d'une technique d'amorçage sur le délai d'installation et la durée d'action du rocuronium $\left(I, 5 \times E D_{95}\right.$, 2,0 $\times E D_{95}$ ) chez les enfants.

Méthode : Quatre-vingt-quatre enfants âgés de un à sept ans et subissant une chirurgie pédiatrique élective ont été recrutés dans cette étude randomisée contrôlée. La fonction neuromusculaire a été évaluée par accélérométrie en réponse à une stimulation simple afin de mesurer le début du bloc neuromusculaire, suivie par une stimulation en train-de-quatre (TOF) au poignet toutes les $15 \mathrm{sec}$. Les enfants ont été randomisés en quatre groupes: les groupes I et 3 ont reçu un placebo de sérum physiologique, suivi une minute plus tard par une dose unique en bolus de rocuronium $0,45 \mathrm{mg} \cdot \mathrm{kg}^{-1}$ iv $\left(I, 5 \times E D_{95}\right)$ et $0,6 \mathrm{mg} \mathrm{kg}^{-1}$ iv $\left(2,0 \times E D_{95}\right)$, respectivement. Les patients des groupes 2 et 4 ont reçu une dose initiale de rocuronium $0,045 \mathrm{mg} \cdot \mathrm{kg}^{-1}$ iv et $0,06 \mathrm{mg} \cdot \mathrm{kg}^{-1} \mathrm{iv}$, respectivement, suivie une minute plus tard par du rocuronium $0,405 \mathrm{mg} \cdot \mathrm{kg}^{-1}$ et 0,54 $\mathrm{mg} \cdot \mathrm{kg}^{-1} \mathrm{iv}$, respectivement.

Résultats : L'amorçage avec le rocuronium a accéléré de façon significative le délai jusqu'au bloc neuromusculaire maximum induit par le rocuronium comparé au placebo [moyenne (intervalle de confiance $95 \%)$ ] : I22,5 (98-186) vs 92,5 (68-II6) sec (I,5 $\times E D_{95}$, groupe I vs groupe $\left.2, P<0,05\right)$ et $85(60-142)$ vs 55 (48-72) sec $\left(2,0 \times E D_{95}\right.$, groupe 3 vs groupe $\left.4, P<0,05\right)$, respectivement. La récupération spontanée d'un ratio TOF $\geq 0,9$ était dépendante de la dose et n'a pas été influencée par l'amorçage.

Conclusion : L'amorçage a accéléré le début de l'action du rocuronium chez les enfants. Un intervalle d'amorçage d'une minute et une dose cumulative de rocuronium I,5 x ED 95 a eu pour résultat un délai de bloc neuromusculaire comparable à celui obtenu avec une dose unique de rocuronium $\left(2,0 \times E D_{95}\right)$.

CAN J ANESTH $2007 / 54: 7$ / pp 538-543

From the Department 1 of Anesthesiology, ${ }^{*}$ Bozen Central Hospital, Bozen, Italy; and the Department of Anesthesiology, $\dagger$ University of Heidelberg, Heidelberg, Germany.

Address correspondence to: Dr. Matthias Bock, Department 1 of Anesthesiology, Bozen Central Hospital, Lorenz Böhler Strasse 5 , I - 39100 Bozen, Italy. Phone: ++39 0471908 673; Fax: ++39 0471909 783; E-mail: matthias.bock@asbz.it

The study was financed by departmental founds. None of the authors has any financial interest with the companies mentioned in the text or in the field of research issued by this article.

Accepted for publication October 5, 2006.

Revision accepted March 29, 2007. 
$\mathrm{R}$

OCURONIUM bromide is characterized by a rapid onset of neuromuscular block and intermediate duration of action. $\mathrm{ED}_{95}$ resulted in accelerated onset of neuromuscular block in children, when mimicking rapid sequence induction. ${ }^{1}$ This increase in dosage, however, has been associated with a considerably prolonged duration of action. ${ }^{1,2}$ For pediatric procedures of short duration, even a loading dose of rocuronium as low as $0.6 \mathrm{mg}$ may result in residual neuromuscular block. The onset of non-depolarizing neuromuscular blocking agents can be hastened by using combinations of neuromuscular blocking drugs ${ }^{3,4}$ or giving a small initial dose of the muscle relaxant before the intubating dose. ${ }^{4-8}$ While the priming technique has been well established generally,, 10 the results of studies evaluating the priming technique with rocuronium are conflicting. In adults, the onset of action of rocuronium was accelerated by different priming techniques ${ }^{4}$ when short priming intervals were used. ${ }^{11}$ In contrast, no effects of priming were observed by other investigators using the classic priming principle. ${ }^{12,13}$ In children, priming had no effect on onset time of neuromuscular block when a total dose of rocuronium $2.0 \times \mathrm{ED}_{95}$ was used. ${ }^{14}$ We hypothesized, when using a modified priming technique, that a smaller cumulative dose of rocuronium $\left(1.5 \times \mathrm{ED}_{95}\right)$ might result in a comparable onset of neuromuscular block as a large single dose of rocuronium $\left(2.0 \times \mathrm{ED}_{95}\right)$ in children. We undertook a randomized controlled trial to test this hypothesis. The primary efficacy variable was the onset time of rocuronium neuromuscular block. Secondary study endpoints included intubating conditions, and the time from bolus injection of the study drug to spontaneous recovery of the $\mathrm{T}_{4} / \mathrm{T}_{1}$ ratio to 0.9 .

\section{Methods}

This was a prospective, randomized, double-blind study. Following approval by the local Ethics Committee and after obtaining written informed consent from the parents, ASA class I or II children between one and seven years undergoing elective surgical procedures at the department of pediatric surgery of the University of Heidelberg, Germany were enrolled. Patients were excluded if they had a history of neuromuscular disease or malignant hyperthermia, had decreased kidney or liver function, or were receiving antibiotics. The patients were randomly allocated by a computer-generated randomization schedule into one of four groups to receive rocuronium doses equivalent to $1.5 \times \mathrm{ED}_{95}$ or $2.0 \times \mathrm{ED}_{95}$, with or without priming. The priming dose was chosen according to previous studies, ${ }^{4,10,11}$ and the priming interval was based on data from our pilot studies.

\section{Study design}

All children received premedication with oral midazolam $0.45 \mathrm{mg} \cdot \mathrm{kg}^{-1}$ given between 30 and $45 \mathrm{~min}$ prior to induction of anesthesia. Standard monitors were applied [electrocardiogram, non-invasive blood pressure, arterial oxygen saturation $\left(\mathrm{SaO}_{2}\right)$, endtidal carbon dioxide $\left(\mathrm{ET}_{\mathrm{T}} \mathrm{CO}_{2}\right)$, nasal temperature] and a neuromuscular transmission monitor (TOFGUARD $^{\mathrm{TM}}$; Organon Teknika, Turnhout, Belgium) was attached. After establishing intravenous access using cutaneous local anesthesia $\left(\right.$ EMLA $^{\mathrm{TM}}$ ) general anesthesia was induced with propofol $2.5-3.5 \mathrm{mg} \cdot \mathrm{kg}^{-1}$ iv followed by inhalation of a mixture of $60 \%$ nitrous oxide in oxygen. Following loss of eyelash reflex, the study drug was given via a freely-running intravenous infusion in two divided doses, one minute apart as described below. After maximum neuromuscular block was achieved and the onset parameters were recorded, the patient's trachea was intubated and intubating conditions were assessed. Anesthesia was maintained with sevoflurane (1.5 MAC end-tidal concentration, age-adjusted) supplemented with nitrous oxide $60 \%$ in oxygen. After intubation of the trachea, mechanical ventilation of the lungs was instituted maintaining end-tidal carbon dioxide $\left(\mathrm{P}_{\mathrm{ET}} \mathrm{CO}_{2}\right)$ between 32 and $40 \mathrm{mmHg}$. Nasal temperature was kept between 36.0 and $37.0^{\circ} \mathrm{C}$ by a forced air warming device.

\section{Neuromuscular monitoring}

Neuromuscular function was evaluated using acceleromyography (TOF-GUARD ${ }^{\mathrm{TM}}$; Organon Teknika, Turnhout, Belgium). ${ }^{15}$ The ulnar nerve was stimulated at the wrist via surface electrodes with supramaximal $0.1 \mathrm{~Hz}$ single twitches for recording of onset parameters, and train-of-four (TOF) supramaximal square wave impulses of $0.2 \mathrm{msec}$ duration were delivered at $2 \mathrm{~Hz}$ every $15 \mathrm{sec}$ to estimate the time course of neuromuscular block and recovery parameters. ${ }^{16}$ The response of the adductor pollicis muscle was recorded using an acceleration transducer attached over the distal interphalangeal joint to the flexor aspect of the freely mobile thumb. The temperature over the adductor pollicis was maintained above $32.0^{\circ} \mathrm{C} .{ }^{16}$ Acceleromyography was commenced immediately after the injection of propofol: first, a $50-\mathrm{Hz}$ tetanus of five seconds duration was applied in order to ensure signal stabilization, and then the transducer was calibrated. After a stabilization period the study drugs were administered as described below and the resulting neuromuscular activity was monitored. Digitized 
TABLE I Demographic characteristics (mean \pm SD)

\begin{tabular}{lllll}
\hline & $\begin{array}{l}\text { Group 1 } \\
(n=21)\end{array}$ & $\begin{array}{l}\text { Group 2 } \\
(n=20)\end{array}$ & $\begin{array}{l}\text { Group 3 } \\
(n=21)\end{array}$ & $\begin{array}{l}\text { Group 4 } \\
(n=20)\end{array}$ \\
\hline Age $(\mathrm{yr})$ & $4.1 \pm 2.0$ & $4.3 \pm 1.7$ & $3.9 \pm 1.7$ & $3.9 \pm 1.3$ \\
Weight $(\mathrm{kg})$ & $18 \pm 8.4$ & $18 \pm 8.5$ & $18 \pm 9.0$ & $18 \pm 8.5$ \\
Height $(\mathrm{cm})$ & $103 \pm 31.2$ & $100 \pm 31.9$ & $103 \pm 33.9$ & $102 \pm 33.1$ \\
Gender $(\mathrm{m} / \mathrm{f})$ & $16 / 5$ & $16 / 4$ & $19 / 2$ & $17 / 3$ \\
\hline
\end{tabular}

The groups were similar with respect to all variables.

data were recorded onto a memory card supplied with the TOF-GUARD ${ }^{\mathrm{TM}}$ and subsequently processed by an independent investigator not involved in the conduct of anesthesia.

\section{Administration of study drug}

Allocation concealment was achieved with the use of sealed consecutively numbered envelopes. These envelopes were given to our anesthesia nurses who prepared the study drugs prior to induction of general anesthesia. Both the anesthesiologist and the investigator were unaware of the amount of the study drug in the prepared syringes. Children in Groups 1 and 3 received a placebo priming injection with saline, followed one minute later by a single bolus (intubating) dose of rocuronium $0.45 \mathrm{mg} \cdot \mathrm{kg}^{-1} i \mathrm{v}\left(1.5 \times \mathrm{ED}_{95}\right)$ and $0.6 \mathrm{mg} \cdot \mathrm{kg}^{-1}$ iv $\left(2.0 \times \mathrm{ED}_{95}\right)$, respectively. Children in Groups 2 and 4 received a subparalyzing dose of rocuronium $0.045 \mathrm{mg} \cdot \mathrm{kg}^{-1}$ iv and $0.06 \mathrm{mg} \cdot \mathrm{kg}^{-1} i v$, respectively (priming dose), followed one minute later by rocuronium $0.405 \mathrm{mg} \cdot \mathrm{kg}^{-1}$ iv and $0.54 \mathrm{mg} \cdot \mathrm{kg}^{-1}$ iv (intubating dose), respectively. The injection time for the intubating dose of rocuronium was five seconds in all children. ${ }^{16,17}$ The total dose of rocuronium was $0.45 \mathrm{mg} \cdot \mathrm{kg}^{-1}\left(1.5 \times \mathrm{ED}_{95}\right)$ in Groups 1 and 2 and $0.6 \mathrm{mg} \cdot \mathrm{kg}^{-1}\left(2.0 \times \mathrm{ED}_{95}\right)$ in Groups 3 and 4 . In all groups, the time interval between the end of the priming dose or placebo saline injection and administration of the intubating dose of rocuronium was exactly one minute. In all subjects rocuronium was allowed to recover spontaneously; no anticholinesterase medications were administered for reversal.

\section{Statistical considerations}

According to our pilot studies we anticipated the mean time to achieve $90 \%$ depression of first twitch amplitude to require $90 \mathrm{sec}$. Neuromuscular blocking drugs usually have a coefficient of variation for the effective dose between $20 \%-25 \%{ }^{18}$ We therefore judged a reduction of the onset time by at least $30 \mathrm{sec}$ to be clinically significant. To achieve $80 \%$ power with $\alpha=0.05,21$ patients per group were required.

The following variables of neuromuscular block were assessed: time to $90 \%$ depression of the first twitch ( $\mathrm{T} 1$ ) response, time to maximum block, defined as time from the beginning of the bolus drug injection (i.e., injection of the intubation dose) to abolition of measurable twitches (if the maximal block was $<95 \%$ the endpoint was taken as the first of three consecutive twitches with the same or increasing amplitude); and TOF-ratio $0.9\left(\mathrm{~T}_{4} / \mathrm{T}_{1}=0.9\right)$ respectively, defined as time from the beginning of bolus drug injection to spontaneous recovery of the $\mathrm{T}_{4} / \mathrm{T}_{1}$ ratio to 0.9 . In addition, we assessed the intubating conditions as described recently. ${ }^{16}$

The data are presented as medians and 95\% confidence intervals. Statistical analysis was performed by analysis of variance, and the Student-Newman-Keuls test for pairwise comparisons using the commercial software Medcalc (Medcalc, Dunkirchen, Belgium). Distribution of normality was analyzed using the Kolmogorov-Smirnov test. The Chi-square test was used for statistical comparison of the intubating conditions. $P<0.05$ was considered significant.

\section{Results}

Eighty-four patients who were screened met our inclusion criteria. One child in Group 2 was 23 months and one child belonging to Group 4 was 22 months old. These patients were excluded from the statistical analysis due to age considerations as suggested by recent guidelines. ${ }^{16}$ All remaining 82 children completed the study protocol. The study groups were comparable with respect to age, weight, height, and sex distribution (Table I). No adverse events related to the priming dose and administration of rocuronium were observed during the study period.

Administration of placebo (Groups 1 and 3 ) and the subparalyzing priming dose $\left(0.045 \mathrm{mg} \cdot \mathrm{kg}^{-1}\right.$ and $0.06 \mathrm{mg} \cdot \mathrm{kg}^{-1}$ in Groups 2 and 4 respectively) did not result in a measurable twitch depression in any patient. In all patients, $100 \%$ twitch depression was observed in response to the intubating dose, independently from the dose of rocuronium $\left(1.5 \times \mathrm{ED}_{95}\right.$ or $2.0 \times$ $\mathrm{ED}_{95}$ ). Time to $90 \%$ twitch depression and time to maximal neuromuscular block are presented in Table II. Rocuronium priming significantly accelerated the onset of rocuronium-induced neuromuscular block (Groups 2 and 4) when compared to placebo saline priming (Groups 1 and 3, Figure).

Spontaneous recovery to $\mathrm{a}_{4} / \mathrm{T}_{1}$ ratio $=0.9$ was dose-dependent, but not influenced by the priming technique (Table II). Finally, intubating conditions 


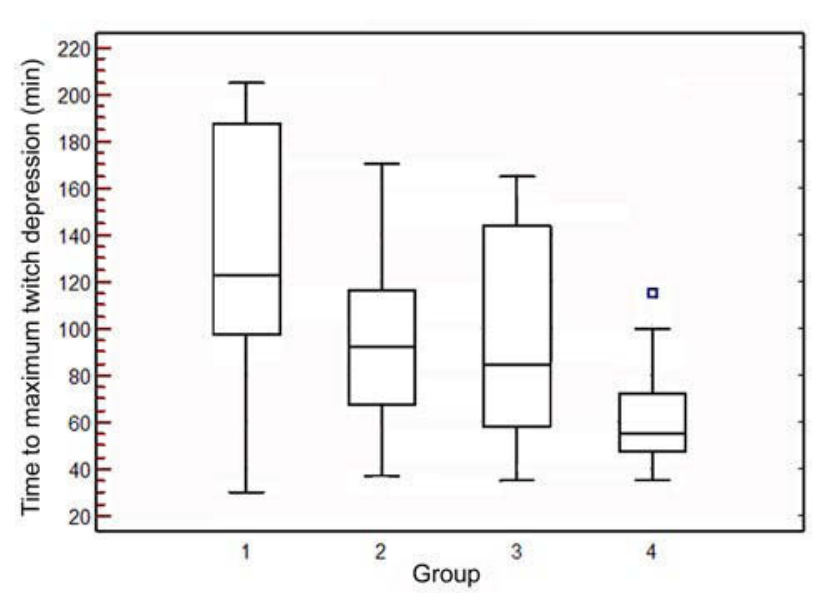

FIGURE Time to maximal neuromuscular block in response to rocuronium in children with priming (Groups 2 and 4 ) or without priming (Groups 1 and 3 ). Children in Groups 1 and 2 received rocuronium $\left(1.5 \times \mathrm{ED}_{95}\right)$ and children in Groups 3 and 4 received rocuronium $(2.0 \times$ $\left.\mathrm{ED}_{95}\right)$, respectively. Box plots represent median, $25^{\text {th }}-75^{\text {th }}$ percentile, and $10^{\text {th }}-90^{\text {th }}$ percentiles. Rocuronium priming accelerated significantly the time to maximal neuromuscular block. $P<0.05$ for Group 4 vs 1,2 (effect of dose and priming) and 3 (effect of priming); $P<0.05$ for Group 3 vs 1 (effect of dose and priming) and 4 (effect of priming); $P<0.05$ for Group 2 vs 1 (effect of priming) and 4 (effect of dose and priming); $P<0.05$ for Group 1 vs 2 (effect of priming) and 3,4 (effect of dose and priming).

were judged as good to excellent in all children, irrespective of the dose of rocuronium (Table III).

\section{Discussion}

Priming enhanced the onset of rocuronium in a pediatric patient population. A priming interval of one minute and a cumulative dose of rocuronium $1.5 \times$ $\mathrm{ED}_{95}$ resulted in an onset of neuromuscular block comparable to a single dose of rocuronium $(2.0 \times$ $\left.\mathrm{ED}_{95}\right)$. The spontaneous recovery profile was not affected by this priming technique.
Our results are in contrast, at least partially, with another study examining the effects of priming on the pharmacodynamics of rocuronium in children ${ }^{14}$ where no acceleration of onset parameters was observed, when a total dose of rocuronium $2.0 \times \mathrm{ED}_{95}$ was given after priming with rocuronium $0.06 \mathrm{mg} \cdot \mathrm{kg}^{-1}$. The discrepancies might be a result of two factors. First, Lee $e t$ al. ${ }^{14}$ administered neuromuscular blocking drugs while children were receiving enflurane/nitrous oxide anesthesia, which might have potentiated the neuromuscular block. Second, the authors used a priming interval of three minutes for their study, in contrast to a shorter one minute priming interval in the present study. Priming intervals which are excessive may prolong onset times. ${ }^{5}$ This might also explain the observations of others where no acceleration of rocuronium onset was observed after priming in adult patients. ${ }^{12,13,19}$

Priming dose, intubating dose and priming interval are important, but distinct variables. ${ }^{10}$ The optimum combination of these three parameters should be established for each non-depolarizing neuromuscular blocking drug in order to obtain a clinically optimal priming technique. While a priming interval of three to four minutes has generally been considered appropriate, ${ }^{10}$ we chose a shorter priming interval for three reasons. First, rocuronium has a faster onset of action than other intermediate-duration neuromuscular blocking drugs. Second, the onset time of neuromuscular blocking drugs may be slightly accelerated in children because of their higher proportional cardiac outputs. Third, we conducted a pilot study which suggested that a one-minute priming interval is optimal, data which are further supported by Abdulatif $e t$ al., ${ }^{11}$ who confirmed that a one-minute priming interval is adequate when using rocuronium as a priming agent in adults. An acceleration of onset time was also observed after a priming interval of two minutes ${ }^{20}$ and three minutes ${ }^{4,8}$ in adults. Only one study comparing a priming interval of two minutes and three minutes reported conflicting results for rocuronium: ${ }^{7}$ the authors observed a significant reduction of the onset time only after a priming interval of three minutes.

TABLE II Time course of action after the administration of rocuronium with and without priming

\begin{tabular}{lllll}
\hline & Group 1 $(n=21)$ & Group 2 $(n=20)$ & Group 3 $(n=21)$ & Group 4 $(n=20)$ \\
\hline Time to 90\% twitch depression $(\mathrm{sec})$ & $90.0(35.1-110.0) \$$ & $52.5(35.0-74.2)$ & $50.0(40.0-85.0)$ & $40.0(33.1-50.0)^{*}$ \\
Time to maximal block $(\mathrm{sec})$ & $122.5(98.1-185.7) \phi \$ \$$ & $92.5(68.1-115.7)$ & $85.0(60.0-142.0) \phi$ & $55.0(48.1-71.9) \&$ \\
TOF $\geq 0.9(\mathrm{~min})$ & $34.0(28.8-36.8)$ & $36.0(29.3-48.2)$ & $42.8(39.8-47.5) \#$ & $46.8(37.5-51.7) \#$ \\
\hline
\end{tabular}

Data are median (95\% confidence interval). TOF $=$ train-of-four. Groups 1 and 2 received rocuronium $0.45 \mathrm{mg} \cdot \mathrm{kg}^{-1} ; \mathrm{Groups}^{3}$ and 4 received rocuronium $0.6 \mathrm{mg} \cdot \mathrm{kg}^{-1}$; in addition priming was used in Groups 2 and 4 . \#P<0.05 for Groups 3 and 4 vs 1 and 2 (effect of dose); $\$ P<0.05$ for Group 1 vs 2 (effect of priming) and 4 (effect of dose and priming); ${ }^{*} P<0.05$ for Group 4 vs 1 (effect of dose and priming); $\& P<0.05$ for Group 4 vs 1,2 (effect of dose and priming) and 3 (effect of priming); $\$ P<0.05$ for Group 1 vs 3 (effect of dose); $\phi P<0.05$ for Group 1 vs 2 and Group $3 v s 4$ (effect of priming). 
TABLE III Intubating conditions

\begin{tabular}{lllll}
\hline $\begin{array}{l}\text { Intubating } \\
\text { condition }\end{array}$ & $\begin{array}{l}\text { Group 1 } \\
(n=21)\end{array}$ & $\begin{array}{l}\text { Group 2 } \\
(n=20)\end{array}$ & $\begin{array}{l}\text { Group 3 } \\
(n=21)\end{array}$ & $\begin{array}{l}\text { Group 4 } \\
(n=20)\end{array}$ \\
\hline Excellent & 18 & 16 & 19 & 18 \\
Good & 3 & 4 & 2 & 2 \\
Pure & 0 & 0 & 0 & 0 \\
\hline
\end{tabular}

Conditions were graded according to the criteria outlined in reference 16. The proportion of patients rated as either good or excellent were similar in all four groups.

In our study, a relatively small dose of rocuronium $1.5 \times \mathrm{ED}_{95}$ had an onset of action which was comparable to that of succinylcholine. After priming and a total dose of rocuronium $2 \times \mathrm{ED}_{90}$ the onset time was even shorter than that observed in another study where a $3 \times \mathrm{ED}_{90}$ dose of rocuronium was used to mimick rapid sequence induction in children. ${ }^{1}$ Thus, when used for rapid sequence induction, rocuronium priming in children not only hastens onset, but also leads to faster recovery from neuromuscular block because a smaller dose of the neuromuscular blocking drug is needed to achieve a comparable response. Duration of action and recovery are dose-dependent and not influenced by priming.

\section{Study limitations}

We used acceleromyography monitored at the ulnar nerve as a surrogate marker to evaluate the degree of paralysis and recovery of the laryngeal musculature. Measuring neuromuscular transmission at the musculature of the larynx is not very feasible in children. We therefore performed accelerometry according to established guidelines ${ }^{16}$ and maintained a period of stabilization of the neuromuscular response prior to administration of the study drugs in order to avoid the so-called "staircase phenomenon". ${ }^{21}$

In accordance with previous studies, we selected $10 \%$ of the intubating dose as the priming dose. It has been suggested that this dose may be associated with untoward effects in awake patients, ${ }^{18}$ and the effect of a smaller priming dose and potential side-effects of priming in children warrant further evaluation. To address the concern, we administered the study drug only after an appropriate level of anesthesia had been attained. While we cannot report on the complications of priming, importantly, we did not observe measurable depression of the twitch response in any patient during the short priming interval. If our priming technique were to be applied in the clinical setting, we would recommend strict adherence to the short priming interval of one minute. Unfortunately, this time interval may be difficult to achieve consistently in younger pediatric patients. We therefore do not recommend routine use of this technique for pediatric anesthesia, but rather, suggest that rocuronium priming may be warranted in limited cases where succinylcholine is contraindicated.

According to current data, a TOF ratio $>0.9$ is required in order to perform extubation of the trachea safely. ${ }^{22,23}$ Therefore, there may be concern regarding the suitability of using rocuronium at a dose of $\geq 0.6$ $\mathrm{mg}$ either with or without priming, for brief pediatric procedures. We recommend the use of rocuronium at a dose equivalent to $2 \times \mathrm{ED}_{95}$ or greater only for cases lasting $>50 \mathrm{~min}$. While priming did not prolong the time course of action and recovery from neuromuscular block after the application of rocuronium $1.5 \times$ $\mathrm{ED}_{95}$ and $2.0 \times \mathrm{ED}_{95}$, faster onset time was observed. Further studies are warranted to determine whether priming can accelerate the onset of neuromuscular block even when using a lower cumulative dose of rocuronium $\left(1 \times \mathrm{ED}_{95}\right)$ in children.

In conclusion, priming with rocuronium accelerates the onset of neuromuscular block in pediatric patients without prolonging recovery time. Rocuronium priming may be a useful tool for situations where succinylcholine is contraindicated. Due to the recognized side effects of priming with neuromuscular blocking drugs, we suggest that priming with rocuronium should be restricted to these situations.

\section{Acknowledgement}

We gratefully acknowledge the expertise of Harry Bauer, MD, Department of Anesthesiology, University of Heidelberg, for his statistical support.

\section{References}

1 Fuchs-Buder T, Tassonyi E. Intubating conditions and time course of rocuronium-induced neuromuscular block in children. Br J Anaesth 1996; 77: 335-8.

2 Magorian T, Flannery KB, Miller RD. Comparison of rocuronium, succinylcholine, and vecuronium for rapid-sequence induction of anesthesia in adult patients. Anesthesiology 1993; 79: 913-8.

3 Gibbs NM, Rung GW, Braunegg PW, Martin DE. The onset and duration of neuromuscular blockade using combinations of atracurium and vecuronium. Anaesth Intensive Care 1991; 19: 96-100.

4 Naguib $M$. Different priming techniques, including mivacurium, accelerate the onset of rocuronium. Can J Anaesth 1994; 41: 902-7.

5 Taboada JA, Rupp SM, Miller RD. Refining the priming principle for vecuronium during rapid-sequence induction of anesthesia. Anesthesiology 1986; 64: 
243-7.

6 England AJ, Margarson MP, Feldman SA. Tracheal intubation conditions after one minute: rocuronium and vecuronium, alone and in combination. Anaesthesia 1997; 52: 336-40.

7 Yavascaoglu B, Cebelli V, Kelebek N, Uckunkaya N, Kutlay O. Comparison of different priming techniques on the onset time and intubating conditions of rocuronium. Eur J Anaesthesiol 2002; 19: 517-21.

8 Schmidt J, Irouschek A, Muenster T, Hemmerling TM, Albrecht $S$. A priming technique accelerates onset of neuromuscular blockade at the laryngeal adductor muscles. Can J Anesth 2005; 52: 50-4.

9 Foldes F. Rapid tracheal intubation with non-depolarizing neuromuscular blocking drugs: the priming principle (Letter). Br J Anaesth 1984; 56: 663.

10 Miller RD. The priming principle. Anesthesiology 1985; 62: 381-2.

11 Abdulatif M, al-Ghamdi A, el-Sanabary M. Rocuronium priming of atracurium-induced neuromuscular blockade: the use of short priming intervals. J Clin Anesth 1996; 8: 376-81.

12 Foldes FF, Nagashima H, Nguyen HD, Schiller WS, Mason MM, Obta $\Upsilon$. The neuromuscular effects of ORG9426 in patients receiving balanced anesthesia. Anesthesiology 1991; 75: 191-6.

13 Hofmockel R, Benad G. Time-course of action and intubating conditions with rocuronium bromide under propofol-alfentanil anaesthesia. Eur J Anaesthesiol Suppl 1995; 11: 69-72.

14 Lee SK, Kim JR, Bai SJ, ShinYS, Nam YT, Cohen SP. Effects of priming with pancuronium or rocuronium on intubation with rocuronium in children. Yonsei Med J 1999; 40: 327-30.

15 Loan PB, Paxton LD, Mirakhur RK, Connolly FM, McCoy EP. The TOF-Guard neuromuscular transmission monitor. A comparison with the Myograph 2000. Anaesthesia 1995; 50: 699-702.

16 Viby-Mogensen J, Engaek J, Eriksson LI, et al. Good clinical research practice (GCRP) in pharmacodynamic studies of neuromuscular blocking agents. Acta Anaesthesiol Scand 1996; 40: 59-74.

17 Viby-Mogensen J, Ostergaard D, Donati F, et al. Pharmacokinetic studies of neuromuscular blocking agents: good clinical research practice (GCRP). Acta Anaesthesiol Scand 2000; 44: 1169-90.

18 Kopman AF, Khan NA, Neuman GG. Precurarization and priming: a theoretical analysis of safety and timing. Anesth Analg 2001; 93: 1253-6.

19 Redai I, Feldman SA. Priming studies with rocuronium and vecuronium. Eur J Anaesthesiol Suppl 1995; 11: $11-3$.

20 Griffith KE, Joshi GP, Whitman PF, Garg SA. Priming with rocuronium accelerates the onset of neuromuscular blockade. J Clin Anesth 1997; 9: 204-7.

21 Kopman AF, Kumar S, Klewicka MM, Neuman GG. The staircase phenomenon: implications for monitoring of neuromuscular transmission. Anesthesiology 2001; 95: 403-7.

22 Kopman AF, Yee PS, Neuman GG. Relationship of the train-of-four fade ratio to clinical signs and symptoms of residual paralysis in awake volunteers. Anesthesiology 1997; 86: 765-71.

23 Eriksson LI, Sundman E, Olsson R, et al. Functional assessment of the pharynx at rest and during swallowing in partially paralyzed humans: simultaneous videomanometry and mechanomyography of awake human volunteers. Anesthesiology 1997; 87: 1035-43. 